\title{
Perbedaan efektivitas home bleaching berbahan carbamide peroxide $10 \%$ dengan home bleaching berbahan non peroxide terhadap gigi premolar rahang atas
}

\author{
Jeanice Felincia ${ }^{1}$, Rudy Djuanda ${ }^{2}$, Angela Evelyna ${ }^{3}$
}

\author{
${ }^{1}$ Departemen Konservasi Gigi, Fakultas Kedokteran Gigi, Universitas Kristen Maranatha, Indonesia \\ 2 Departemen Ilmu Teknologi dan Material Kedokteran Gigi, Fakultas Kedokteran Gigi, Universitas \\ Kristen Maranatha, Indonesia
}

*Korespondensi: jeanicefelincia20@gmail.com

\begin{abstract}
ABSTRAK
Pendahuluan: Terdapat beberapa macam pewarnaan gigi, yaitu eksternal, internal dan gabungan keduanya. Prosedur bleaching menjadi perawatan gigi yang paling digemari untuk mengatasi perubahan warna gigi. Terdapat dua macam prosedur bleaching vital, yaitu home bleaching dan in office bleaching. Bahan yang sering digunakan untuk metode home bleaching adalah carbamide peroxide 10\% yang aman serta efektif memutihkan gigi, namun peroksida cenderung bersifat tidak stabil dan mutagenik dalam konsentrasi tinggi, karena itu dikembangkan bahan bleaching non peroxide.Tujuan penelitian untuk membandingkan efektifitas home bleaching carbamide peroxide $10 \%$ dan non peroxide terhadap gigi premolar rahang atas. Metode: Penelitian dilakukan dengan cara merendam gigi dalam bahan carbamide peroxide 10\% dan non-peroxide hingga batas CEJ selama 14 hari dengan durasi 7 jam per hari. Sampel disimpan dalam inkubator bersuhu $37^{\circ} \mathrm{C}$. Pengukuran warna dilakukan pada hari ke-1, ke-7, dan ke-14 menggunakan spektofotometer Premiere Colorscan SS6200 yang menghasilkan pengelompokan warna CIELAB. Metode analisis data menggunakan $t$-test independent. Hasil: Terdapat perbedaan yang signifikan pada nilai perubahan warna 17.672 pada kelompok perlakuan carbamide peroxide $10 \%$ dan 8.863 pada non peroxide di hari ke-14. Nilai $\mathrm{p}=0.000(<0.005)$ pada kedua perbandingan hari ke-7 dan ke-14. Simpulan: Penggunaan bahan carbamide peroxide 10\% lebih efektif memutihkan gigi dibandingkan bahan non peroxide.
\end{abstract}

Kata kunci: home bleaching, carbamide peroxide, non peroxide, teeth discoloration

\section{The difference in effectiveness of carbamide peroxide 10\% home bleaching material with non peroxide home bleaching material on premolar maxillary teeth}

\begin{abstract}
Introduction: There are several kind of staining, which is external, internal, and combination of both. There're two kinds of vital bleaching procedures, home bleaching and in office bleaching. The most commonly used ingredient for home bleaching technique is carbamide peroxide 10\% which is safe and effective to brighten the teeth, but unstable and mutagenic in high concentration, hence non peroxide bleaching material have been developed. The objective of the study was to compare effectiveness between home bleaching carbamide peroxide 10\% and non peroxide. Methods: The research was conducted by soaking the teeth in carbamide peroxide 10\% and non-peroxide up to CEJ for 14 days with duration of 7 hours per day. Samples are stored in a $37^{\circ} \mathrm{C}$ incubator. Color measurements were performed on the $1^{\text {st }}, 7^{\text {th }}$, and $14^{\text {th }}$ day using Premiere Colorscan SS6200 Spectrophotometer with CIELAB system and data result using independent $t$-test method. Results: There showed a significant difference with the color change value of 17.672 in carbamide peroxide $10 \%$ group and 8.863 in non peroxide group at day $14^{\text {th }}$. $P$-value $=0.000(<0.005)$ on both day $7^{\text {th }}$ and $14^{\text {th }}$ comparison. Conclusion: the use of carbamide peroxide $10 \%$ bleaching material are more effective to whiten teeth compared to non-peroxide bleaching material.
\end{abstract}

Keywords: Home bleaching; carbamide peroxide; non peroxide; teeth discoloration 


\section{PENDAHULUAN}

Banyak orang mengganggap penampilan adalah hal yang terutama karena dapat meninggalkan suatu kesan yang baik jika orang lain menilai seseorang berpenampilan menarik dan mereka akan merasa diterima secara sosial maupun psikologis. Menurut data yang didapatkan oleh ADA (American Dental Association), lebih dari dua dekade terakhir prosedur bleaching gigi telah menjadi perawatan gigi estetik yang paling populer untuk mengatasi pewarnaan pada gigi. ${ }^{1}$ Terdapat dua macam pewarnaan gigi, yaitu eksternal, internal, dan bisa juga gabungan dari keduanya. ${ }^{2,3}$

Pewarnaan eksternal terjadi pada bagian luar dari enamel yang biasanya disebabkan oleh pewarnaan langsung dari makanan dan minuman yang dikonsumsi, seperti kopi, teh, tembakau, bakteri kromogenik, dan bahan kimia atau obatobatan, sedangkan pewarnaan internal terjadi di dalam struktur gigi yang dapat disebabkan karena penumpukan bahan- bahan dalam struktur gigi yang menginduksi enamel dan dentin sebelum gigi erupsi (pre eruptive) maupun setelah erupsi (post eruptive). ${ }^{3,4}$

Prosedur pemutihan gigi biasanya dilakukan secara kimiawi, dapat dilakukan secara eksternal untuk gigi yang vital, atau bisa juga bleaching nonvital yang dilakukan secara intrakoronal pada gigi yang sudah dirawat saluran akar. ${ }^{3}$ Prosedur bleaching vital dapat dilakukan di klinik dokter gigi maupun di rumah. ${ }^{1}$ Haywood dan Heyman adalah orang yang pertama kali memperkenalkan prosedur home bleaching pada gigi vital dengan menggunakan night guard dan carbamide peroxide $10 \%$. Keuntungan dari sistem home bleaching ini adalah penggunaannya yang relatif mudah, terjangkau, aman dan persentase kesuksesan yang tinggi. ${ }^{5}$

Teknik home bleaching menggunakan bahan carbamide peroxide dengan konsentrasi 10- 15\% yang sesuai dengan ketentuan ADA. ${ }^{1}$ Bahan dasar peroksida memiliki sifat yang cenderung tidak stabil dan mutagenik pada konsentrasi tinggi serta dapat mempegaruhi jaringan lunak di sekitar gigi menjadi rusak, oleh karena itu, sistem bleaching dengan bahan dasar non peroxide juga mulai dikembangkan. ${ }^{6}$

Sodium bicarbonate memiliki banyak peran dalam bidang kedokteran gigi karena banyak digunakan dalam pasta gigi dan obat kumur. ${ }^{7}$ Selain sodium bicarbonate, terdapat bahan lain yaitu EDTA (Ethylenediaminetetraacetic Acid) yang merupakan chelating agent yang digunakan untuk menghilangkan smear layer pada perawatan saluran akar gigi, selain itu EDTA pun dapat mengkalsifikasi jaringan dengan cara mengikat ion kalsium. .,9,10,11 $^{2}$ Penelitian yang dilakukan oleh Endang Suprastiwi (2005), perawatan pemutihan gigi menggunakan bahan Carbamide Peroxide dapat meningkatkan warna gigi hingga 2-5 tingkat.

Warna gigi tersebut dapat bertahan hingga 1-3 tahun. ${ }^{12}$ Penelitian yang dilakukan oleh Dian Paramita (2015) menunjukan hasil bahwa baking soda (Sodium Bicarbonate) juga berpengaruh untuk membersihkan stain/ pewarnaan pada gigi. Hal tersebut dapat dilihat dari 30 orang responden yang memiliki rata- rata pewarnaan dengan skor pewarnaan buruk, $^{12}$ diantaranya mengalami perubahan skor rata- rata menjadi pewarnaan baik. ${ }^{13}$ Uraian hasil penelitian diatas mendorong peneliti untuk meneliti perbedaan efektifitas antara home bleaching berbahan carbamide peroxide $10 \%$ dan home bleaching berbahan non peroxide terhadap gigi premolar rahang atas karena belum ditemukan penelitian yang melihat perbedaan terhadap bahan carbamide peroxide $10 \%$ dibandingkan dengan bahan non peroxide secara langsung.

\section{METODE}

Desain penelitian yang akan digunakan adalah metode eksperimental laboratorium murni dengan menggunakan 32 sampel gigi premolar rahang atas post ekstransi yang dibagi menjadi 2 kelompok perlakuan yaitu 16 gigi dengan perlakuan home bleaching berbahan carbamide peroxide 10\% dan 16 gigi dengan perlakuan home bleaching berbahan non peroxide. Objek penelitian yakni 32 gigi premolar rahang atas post ekstraksi untuk keperluan perawatan ortodontik. Objek penelitian dipilih sesuai dengan kriteria inklusi dan eksklusi yang sudah ditentukan.

Alat yang digunakan antara lain spektofotometer, inkubator, tabung reaksi, rak tabung reaksi, pinset, masker, sarung tangan, alat tulis, tisu. Bahan yang digunakan antara lain 32 gigi premolar rahang atas, home bleaching carbamide peroxide $10 \%$, home bleaching non peroxide, cat kuku bening, aquades steril, dan salin. Sampel penelitian berupa 32 gigi premolar rahang atas post ekstraksi. Ukuran sampel ditentukan berdasarkan 
tujuan penelitian yaitu melihat perbedaan pengaruh antara satu kelompok sampel dengan kelompok lainnya, sehingga untuk setiap kelompok perlakuan diperlukan 16 sampel. Kriteria inklusi sampel adalah gigi premolar permanen, akar tumbuh sempurna, gigi tidak di restorasi, dan gigi tidak karies. Kriteria eksklusi sampel yaitu gigi berkalkulus, gigi retak/ fraktur, gigi atrisi berlebihan, dan gigi dengan pewarnaan internal.

Variabel bebas yaitu home bleaching berbahan carbamide peroxide $10 \%$ dan home bleaching berbahan non peroxide. Variabel terikat yaitu warna gigi dengan parameter CIELAB.

Persiapan Sampel, spesimen penelitian terdiri dari 32 gigi premolar rahang atas post ekstraksi dengan kriteria insklusi yang telah direndam dalam larutan salin. Spesimen secara acak dibagi menjadi dua kelompok dengan masing- masing 16 sampel yaitu kelompok perlakuan carbamide peroxide $10 \%$ dan kelompok perlakuan non peroxide.

Sampel gigi diberi kode pada bagian sementum menggunakan spidol tahan air, kemudiah dari cemento enamel junction hingga apeks akar diulaskan cat kuku bening. Sampel diberi kode CP1CP16 untuk kelompok perlakuan menggunakan Carbamide Peroxide $10 \%$ dan kode NP1- NP16 pada kelompok perlakuan menggunakan bahan Non Peroxide. Prosedur Bleaching, masing - masing sampel gigi yang telah diberi kode dan telah diukur warnanya diberi perlakuan menggunakan carbamide peroxide $10 \%$ untuk sampel dengan kode CP1CP16 dengan cara memasukan sampel pada tabung reaksi yang telah berisi bahan bleaching carbamide peroxide $10 \%$ dan spesimen dengan kode NP1NP16 dilakukan perlakuan yang sama dengan menggunakan bahan bleaching non peroxide.

Prosedur dilakukan selama 7 jam dari pukul 07.00-14.00. Selama diberi perlakuan, sampel disimpan di dalam inkubator dengan tujuan untuk menjaga kelembapan dan temperaturnya. Suhu inkubator diatur menyerupai suhu normal rongga mulut yaitu $37^{\circ} \mathrm{C}$. Setelah 7 jam, sampel dicuci menggunakan aquades steril kemudian dikeringkan.

Selama tidak diberi perlakuan, spesimen diletakan dalam wadah yang kering, tertutup, dan bebas dari agen yang menyebabkan pewarnaan kemudian dimasukan ke dalam inkubator. Proses bleaching diulangi selama 14 hari. Pengukuran warna dilakukan sebanyak 3 kali pada hari ke-1, ke7, dan ke-14 menggunakan spektofotometer dengan pengelompokan dan deskripsi warna CIE LAB dengan tiga parameter. Parameter $L^{*}$ merepresentasikan derajat warna hitam dan putih (value), sedangkan $a^{*}$ dan $b^{*}$ merepresentasikan sifat warna kemerahhijauan dan kekuning-kebiruan.

Metode pengukuran warna diawali dengan kalibrasi spektofotometer Premiere Colorscan SS 6200 menggunakan white tile. Setelah kalibrasi, sampel gigi diletakan di depan area view ukuran kecil dengan bantuan selotip. Kemudian sampel gigi ditembakan cahaya D- 65 dan menggunakan penerangan sinar UV (Ultra Violet). Setelah ditembakan cahaya, nilai warna dengan parameter LAB akan muncul di computer dengan software One Constant Colorlab + Color Matching.

Metode analisis data yang digunakan dalam penelitian ini adalah uji t tidak berpasangan (independent t-test) dengan syarat uji normalitas terpenuhi, uji normalitas yang dilakukan adalah uji Shapiro-Wilk. Namun, apabila normalitas data tidak terpenuhi, maka menggunakan uji Mann Whitney, dengan menggunakan tingkat kepercayaan (confident interval) 95\% dan error $(\alpha) 5 \%$.

Pengujian data dilakukan mengguankan software SPSS versi I 20.0. Penelitian ini dilakukan selama 14 hari dengan durasi selama 7 jam setiap harinya menggunakan 32 sampel gigi kriteria inklusi yang dibagi kedalam 2 kelompok dengan pembagian secara acak dan masing - masing kelompok terdiri dari 16 sampel gigi. Pengukuran warna gigi dilakukan pada hari ke-1, ke-7 dan ke-14 menggunakan spektofotometer Premiere Colorscan SS 6200 yang menghasilkan pengelompokan warna dengan sistem pewarnaan CIELAB. Besar nilai rata - rata value $\left(L^{*}\right)$, kroma kemerahan-kehijauan $\left(a^{*}\right)$, dan kroma kekuningan - kebiruan pada masing masing kelompok perlakuan .

\section{HASIL}

Penelitian ini dilakukan selama 14 hari dengan durasi selama 7 jam setiap harinya menggunakan 32 sampel gigi kriteria inklusi yang dibagi kedalam 2 kelompok dengan pembagian secara acak dan masing - masing kelompok terdiri dari 16 sampel gigi. Pengukuran warna gigi dilakukan pada hari ke-1, ke-7 dan ke-14 menggunakan spektofotometer Premiere Colorscan SS 6200 yang menghasilkan pengelompokan warna dengan sistem pewarnaan CIELAB. Besar nilai rata - rata value $\left(\mathrm{L}^{*}\right)$, kroma kemerahan-kehijauan $\left(\mathrm{a}^{*}\right)$, 
Tabel 1- rerata nilai value $\left(\mathrm{l}^{*}\right)$, kroma kemerahan - kehijauan $\left(\mathrm{a}^{*}\right)$, dan kroma kekuningan - kebiruan (b*)

\begin{tabular}{|c|c|c|c|}
\hline & $\begin{array}{l}\text { Sebelum } \\
\text { perlakuan }\end{array}$ & $\begin{array}{c}\text { Setelah aplikasi } \\
\text { bleaching hari ke-7 }\end{array}$ & $\begin{array}{c}\text { Setelah aplikasi } \\
\text { bleaching hari ke-14 }\end{array}$ \\
\hline \multicolumn{4}{|c|}{ Value (L*) } \\
\hline Carbamide peroxide $10 \%$ & 63,958 & 77,615 & 79,998 \\
\hline Non Peroxide & 65,939 & 71,310 & 73,559 \\
\hline \multicolumn{4}{|c|}{ Kroma kemerahan - kehijauan (a*) } \\
\hline Carbamide peroxide $10 \%$ & 1,825 & 0,381 & $-0,140$ \\
\hline Non Peroxide & 1,669 & 1,497 & 1,169 \\
\hline \multicolumn{4}{|c|}{ Kroma kekuningan - kebiruan (b*) } \\
\hline Carbamide peroxide $10 \%$ & 13,034 & 10,871 & 9,059 \\
\hline Non Peroxide & 14,215 & 13,515 & 13,291 \\
\hline
\end{tabular}

Tabel 2 - perubahan warna $\left(\delta \mathrm{e}^{*}\right)$ setelah aplikasi bleaching hari ke-7 dan ke-14

\begin{tabular}{ccc}
\hline & Hari ke- & Hari ke- 14 \\
\hline $\begin{array}{c}\text { Carbamide Peroxide } \\
10 \%\end{array}$ & 14.548 & 17.672 \\
Non Peroxide & 6.221 & 8.863 \\
\hline
\end{tabular}

Tabel 3 - hasil uji t perubahan warna $\left(\delta \mathrm{e}^{*}\right)$

\begin{tabular}{|c|c|c|c|c|c|c|}
\hline & Hari & Rata - Rata & $\begin{array}{l}\text { Standar } \\
\text { Deviasi }\end{array}$ & $\mathbf{t}$ & $\mathbf{p}$ & Ket. \\
\hline Carbamide Peroxide 10\% & \multirow[t]{2}{*}{7} & 14.11006 & 3.502934 & \multirow[t]{2}{*}{7.323} & \multirow[t]{2}{*}{0.000} & \multirow{2}{*}{$*$} \\
\hline Non Peroxide & & 5.78381 & 2.900214 & & & \\
\hline $\begin{array}{c}\text { Carbamide } \\
\text { Peroxide 10\% }\end{array}$ & \multirow[t]{2}{*}{14} & 16,79663 & 3.080560 & \multirow[t]{2}{*}{8.238} & \multirow[t]{2}{*}{0.000} & \multirow{2}{*}{$*)$} \\
\hline Non Peroxide & & 7.98800 & 2.966903 & & & \\
\hline
\end{tabular}

Tabel 4 - hasil uji t nilai value $\left(1^{*}\right)$

\begin{tabular}{|c|c|c|c|c|c|c|}
\hline & Hari & Rata - Rata & $\begin{array}{l}\text { Standar } \\
\text { Deviasi }\end{array}$ & $\mathbf{t}$ & $\mathbf{p}$ & Ket. \\
\hline $\begin{array}{c}\text { Carbamide } \\
\text { Peroxide } 10 \% \\
\text { Non Peroxide }\end{array}$ & 7 & $\begin{array}{l}77.614688 \\
71.309500\end{array}$ & $\begin{array}{l}2.460169 \\
3.864242\end{array}$ & 5.51 & 2.79472E-06 & *) \\
\hline $\begin{array}{l}\text { Carbamide Peroxide } 10 \% \\
\text { Non Peroxide }\end{array}$ & 14 & 79.997563 & 2.118381 & 5.52 & $2.70281 \mathrm{E}-06$ & *) \\
\hline
\end{tabular}

Tabel 5 - hasil uji t nilai kroma kemerahan - kehijauan (a*)

\begin{tabular}{|c|c|c|c|c|c|c|}
\hline & Hari & Rata - Rata & Standar Deviasi & $\mathbf{t}$ & $\mathbf{p}$ & Ket. \\
\hline $\begin{array}{c}\text { Carbamide } \\
\text { Peroxide 10\% }\end{array}$ & 7 & 0.381125 & 0.616683 & -3.92 & 0.000235395 & *) \\
\hline Non Peroxide & & 1.497188 & 0.956161 & & & \\
\hline $\begin{array}{c}\text { Carbamide } \\
\text { Peroxide } 10 \%\end{array}$ & 14 & -0.135938 & 0.478784 & -5.48 & $2.70281 \mathrm{E}-06$ & $*)$ \\
\hline Non Peroxide & & 1.168625 & 0.822401 & & & \\
\hline
\end{tabular}


Tabel 6 - hasil uji t nilai kroma kekuningan - kebiruan (b*)

\begin{tabular}{|c|c|c|c|c|c|c|}
\hline & Hari & Rata - Rata & $\begin{array}{l}\text { Standar } \\
\text { Deviasi }\end{array}$ & $\mathbf{t}$ & $\mathbf{p}$ & Ket \\
\hline $\begin{array}{c}\text { Carbamide } \\
\text { Peroxide 10\% }\end{array}$ & \multirow[t]{2}{*}{7} & 10.871000 & 2.519852 & \multirow[t]{2}{*}{-2.17} & \multirow[t]{2}{*}{0.019033272} & \multirow[t]{2}{*}{$*$ ) } \\
\hline Non Peroxide & & 13.515188 & 4.172537 & & & \\
\hline $\begin{array}{c}\text { Carbamide } \\
\text { Peroxide 10\% }\end{array}$ & \multirow[t]{2}{*}{14} & 9.058938 & 1.948448 & \multirow[t]{2}{*}{-4.97} & \multirow[t]{2}{*}{$1.26585 \mathrm{E}-05$} & \multirow[t]{2}{*}{ *) } \\
\hline Non Peroxide & & 13.290625 & 2.792917 & & & \\
\hline
\end{tabular}

dan kroma kekuningan - kebiruan pada masing - masing kelompok perlakuan dapat dilihat pada tabel 1. Perubahan warna masing- masing kelompok perlakuan pada hari ke-7 dan ke-14 dapat dilihat pada tabel 2. Tabel 2 menjelaskan bahwa terjadi peningkatan perubahan warna pada masing- masing kelompok perlakuan dari hari ke-7 hingga hari ke14, yaitu sebesar 3.124 pada kelompok perlakuan carbamide peroxide $10 \%$ dan sebesar 2.642 pada kelompok perlakuan non peroxide.

Data perubahan warna pada kedua kelompok memiliki distribusi normal dan dilanjutkan dengan uji t tidak berpasangan (t-test independent). Pada kedua kelompokbahan bleaching carbamide peroxide $10 \%$ maupun non peroxide terjadi perubahan warna $\left(\Delta \mathrm{E}^{*}\right)$ yang bermakna secara statistik pada hari ke-7 dan hari ke-14 Tabel 3, tabel 4, tabel 5 dan tabel 6 . menjelaskan hasil analisis statistik uji $\mathrm{t}$ tidak berpasangan terhadap nilai $\Delta \mathrm{E}^{*}, \mathrm{~L}^{*}, \mathrm{a}^{*}$, dan $\mathrm{b}^{*}$ pada masing- masing keompok perlakuan pada hari ke-7 dan ke-14. Dapat dilihat nilai p pada masing- masing nilai dan perlakuan adalah $\mathrm{p}<0$ 0.05.Dengan demikian dapat disimpulkan bahwa terdapat perbedaan efektifitas antara penggunaan home bleaching berbahan carbamide peroxide $10 \%$ dan home bleaching berbahan non peroxide terhadap gigi premolar rahang atas yang signifikan secara statistik.

\section{PEMBAHASAN}

Hasil penelitian dan olah data secara statistik, didapatkan hasil penelitian yang signifikan terhadap perbedaan efektifitas penggunaan home bleaching berbahan carbamide peroxide $10 \%$ dan non peroxide terhadap gigi premolar rahang atas. Pada penelitian ini, digunakan carbamide peroxide $10 \%$ yang merupakan bahan yang paling sering digunakan dalam proses home bleaching dan telah disetujui oleh American Dental Association (ADA) sebagai bahan yang aman serta efektif untuk memutihkan gigi, selain cabamide peroxide 10\%, digunakan juga bahan non peroxide yang terdiri dari bahan sodium bikarbonat atau disebut juga baking soda serta EDTA (Ethylenediaminetetraacetic Acid). Telah banyak penelitian yang membandingkan antar bahan bleaching carbamide peroxide maupun hydrogen peroxide seperti yang telah dilakukan oleh Andhita Hervin pada tahun 2014 yang membandingkan antara bahan bleaching carbamide peroxide $10 \%$ dan $15 \%$, namun belum ditemukan penelitian yang membandingkan antara bahan bleaching berbahan carbamide peroxide dengan bahan non peroxide. Penelitian dilakukan selama 14 hari dengan pengaplikasian selama 7 jam setiap harinya sesuai anjuran penggunaan home bleaching ${ }^{1,14}$. Perlakuan pada sampel dilakukan di dalam tabung reaksi yang disimpan di dalam inkubator dengan suhu $37^{\circ} \mathrm{C}$ sesuai suhu normal rongga mulut. Pengukuran warna menggunakan spektofotometer yang merupakan metode objektif, akurat, dan fleksibel dalam melakukan pengukuran warna dan memberikan data spektral cahaya dalam ruang warna CIELAB. ${ }^{40}$

Sampel diberi perlakuan dengan cara direndam pada bahan home bleaching carbamide peroxide $10 \%$ dan non peroxide hingga batas cementoenamel junction sesuai dengan penggunaan home bleaching yang pertama kali diperkenalkan oleh Haywood dan Heyman dengan cara mengaplikasikan bahan home bleaching pada nightguard yang dibuat di laboratorium hingga menutupi seluruh permukaan enamel gigi tanpa perluasan tray yang berlebihan pada bagian mukosa untuk menghindari terjadinya iritasi.,14 Masing - masing bahan bleaching baik carbamide peroxide $10 \%$ maupun non peroxide terbukti dapat memutihkan gigi yang mengalami pewarnaan, hal tersebut terbukti setelah sampel diaplikasikan bahan bleaching selama 14 hari terjadi perubahan warna menuju warna yang lebih putih dibandingkan dengan warna sebelum sampel diberi perlakuan. Dalam penelitiannya, Charles J. dan Paul A. 
menyatakan bahwa warna gigi manusia dilihat dalam ruang warna CIELAB memiliki nilai L* antara 50-95, nilai a* antara (-2)-10, dan nilai $\mathrm{b}^{*}$ antara 8-25. Nilai $\Delta \mathrm{E}^{*}$ yang dapat terlihat secara visual dengan kondisi pencahayaan yang optimal dan dapat diterima secara klinis berkisar dari 1.0-3.3, sedangkan $\Delta \mathrm{E}^{*}<1$ tidak dapat terlihat oleh mata manusia, dan apabila $\Delta \mathrm{E}^{*}>3.33$, warna mudah diobservasi, tetapi nilai perubahan warna ini tidak dapat diterima secara klinis. ${ }^{15}$

Mekanisme pemutihan yang baik akan meningkatkan nilai $L^{*}$ yang secara visual terlihat lebih terang serta penurunan nilai $a^{*}$ dan $b^{*}$. Nilai $\mathrm{L}^{*}$ merupakan parameter pengukuran warna paling tepat untuk melakukan perbandingan pada penelitian eksperimental guna menguji keberhasilan perawatan bleaching. ${ }^{16,17,18}$ Penelitian yang dilakukan oleh penulis, didapatkan hasil rata- rata perubahan warna dari hari ke-7 dan ke-14. Kelompok perlakuan menggunakan bahan carbamide peroxide 10\% memiliki nilai rata- rata perubahan warna di hari ke-7 sebesar 14.548 dan 17.672 di hari ke- 14, sedangkan pada kelompok perlakuan non peroxide adalah 6.221 di hari ke-7 dan 8.863 di hari ke-14.

Hari ke-7 dan ke-14, dapat dilihat nilai pyang membandingkan antara nilai pada masing-masing kelompok perlakuan memiliki hasil yang signifikan, yaitu $p=0.000(<0.005)$. Selisih perubahan warna pada kelompok perlakuan carbamide peroxide 10\% dengan nilai 3.124 lebih besar dibandingkan kelompok perlakuan non peroxide yang bernilai 2.642, hal tersebut menunjukan bahwa bahan bleaching carbamide peroxide 10\% lebih efektif memutihkan gigi dibandingkan dengan bahan bleaching non peroxide baik dilihat secara visual dan uji statistik.

Definisi bleaching gigi merupakan proses yang melibatkan bahan kimia aktif yang menyebabkan peningkatan persepsi warna putih menjadi lebih terang, sedangkan pemutihan gigi merupakan proses yang menghasilkan warna gigi menjadi lebih terang dengan cara apapun.Mekanisme bleaching gigi pada bahan carbamide peroxide terjadi akibat reaksi redoks dari radikal bebas kuat yang dihasilkan dari penguraian $\mathrm{CH}_{6} \mathrm{~N}_{2} \mathrm{O}_{3}$ dimana radikal bebas akan memecahkan molekul kromofor yang tereduksi dan hanya sedikit memantulkan cahaya menjadi fragmen kecil tidak berwarna, sedangkan mekanisme pemutihan gigi yang terjadi pada bahan non peroxide terjadi akibat sifat abrasifitas bahan sodium bikarbonat. Selain sifat abrasifitasnya, sodium bikarbonat juga memiliki sifat alkaloid (basa) yang dapat membersihkan. ${ }^{27,47}$ Sama seperti sabun, sifat membersihkan disebabkan oleh proses kimia koloid. ${ }^{48}$

Selain sodium bikarbonat, EDTA yang terdapat pada bahan non peroxide juga memiliki peran untuk melarutkan bahan oganik melalui chemomechanical effect. EDTA sebagai bahan khelat dapat mengikat ion logam yang merupakan komponen penyebab pewarnaan gigi. Meskipun pada bahan non peroxide terdapat reaksi kimia, tetapi tidak mengoksidasi sebaik peroksida yang memiliki radikal bebas kuat. ${ }^{19}$.

\section{KESIMPULAN}

Terdapat perbedaan efektifitas penggunaan home bleaching berbahan carbamide peroxide 10\% dibandingkan dengan home bleaching berbahan non peroxide terhadap gigi premolar rahang atas dan carbamide peroxide 10\% lebih efektif dibandingkan dengan bahan non peroxide

\section{DAFTAR PUSTAKA}

1. ADA Council on Scientific Affairs. Tooth Whitening/Bleaching:TreatmentConsiderations for Dentist and Their Patients. American Dental Association September 2009.

2. Suchetha A, Khawar S, Mundinamane DB, Apoorva SM, Bhat D, Govindappa L. All About Dental Stains : A Review (Part 1). Annals of Dental Specialty April- June 2016; (4): 41- 46.

3. Dahl JE, Pallesen U. Tooth Bleaching - A Criical Review of The Biological Aspects. Crit Rev Oral Biol Med 2003; 14(4): 292-304.

4. Carey CM, Tooth Whitening: What We Now Know. The Journal of Evidence- Based Dental Practice: 2014: 1-17

5. Meiyestri Dwi Riani, Fadil Oenzil, Nila Kasuma. Pengaruh Aplikasi Bahan Pemutih Gigi Karbamid Peroksida 10\% dan Hidrogen Peroksida 6\% Secara Home Bleaching Terhadap Kekerasan Permukaan Email Gigi. Jurnal Kesehatan Andalas 2015; 4(2): 346-352.

6. Wang X, Klocke A, Mihailova, B, Hill M, Fittschen U, Bismayer U, et al. Side Effects of a Non Peroxide Based Home Bleaching Agent on Dental Enamel. Journal of Biomedical Material Reseach 2009; 
195-204.

7. Silhacek KJ, Taake KR. Sodium Bicarbonate and Hydrogen Peroxide : The Effect on the Growth of Streptococcus Mutans. Journal of Dental Hygene October 2005; 4(79): 1-7.

8. Gin Chen, Yu Chao Chang. Effects of Liquid and Paste Type EDTA on Smear Layer Removal During Rotary Root Canal Instrumentation. Journal of Dental Sciences 2011; (6): 41-47.

9. Apendi, Hanum Tajrihani. Perbedaan Jumlah Eritrosit Darah EDTA 10\% dan Darah Natrium Sitrat 3,8\%. Unergraduate Thesis, Universitas Muhammadiyah Semarang 2017

10. Swaran JSF,Vidhu Pachauri. Chelation in Metal Intoxication. International Journal of Environmental Research and Public Health 2010; 7: 2745-2788.

11. AM Fuadi, Harald Brelid. Benefits of A Chelating Stage Prior to Peroxide Bleaching. Jurnal Teknik Gelagar 2006; 17(2): 91-97.

12. Endang Suprastiwi. Penggunaan Karbamid Peroksida Sebagai Bahan Pemutih Gigi.Fakultas Universitas Kedokteran Gigi Universitas Indonesia 2005: 12(3): 139-145.

13. Dian Paramita. Pemanfaatan Bakin Soda untuk Membersihkan Stain pada Gigi Perokok Di Puskesmas Karang Pule. GaneÇ Swara September 2015; 2(9): 108-111.

14. Greenwall L. Bleaching Techniques in Restorative Dentistry. New York: Martin Dunitz; 2001.

15. Andhita Hervin. Efektivitas Karbamid Peroksida 10\% dan 15\% Terhadap Diskolorasi Ekstrinsik
Oleh Kopi. Department of Dental Material, Faculty off Dentistry, Universitas Indonesia 2014.

16. Rakesh V, Girish P, Shikha K, Akashi C, Manjit K, Toral S. Basic Color in Dentistry : A Review. IOSR Journal of Dental and Medical Sciences; 2014: 13(9):78-85.

17. Goodcare CJ, Sagel PA. Dental Esthetics in Pratice Part 3 - Understanding Color and Shade Selection: Dental Care: 2011.

18. Dietschi D, Rossier S, Krejci I. In Vitro Colorimetric Evaluation of the Efficiency of Various Bleaching Methods and Products. Quintessence Int; 2008; 37(7): 515-26.

19. Yiming Li. Stain Removal and Whiening by Baking Soda Dentifrice. Journal of the American Dental Association; 2017: 20S-26S.

20. Morgan, Ashvina. Perubahan Score Bleachguide, Nilai Kecerahan dan Kekerasan Enamel Gigi Sebelum dan Sesudah Perlakuan Bleaching dengan Karbmid Peroksida 35\%. University of Sumatera Utara Institutional Repository: 2015.

21. Jim D. Sodium Bicarbonate: Should it be Considered As A Treatment. Journal of Emergency Medical Services: 2010.

22. Shintia, Mega. Pembuatan Sabun Padat (Rasio Tallow - Minyak Kelapa - Minyak Jagung. Politeknik Negri Sriwijaya: 2016.

23. Rahmi Alma, Endang Suprastiwi, Munnyati Usman. Pemutihan Gigi Teknik Home Bleaching dengan Menggunakan Karbamid Peroksida. Departemen Ilmu Konservasi Gigi FKG UI 2006; 254-259 